\title{
CSF, plasma viral load and HIV associated dementia
}

\author{
Kevin Robertson, Susan Fiscus, Catherine Kapoor, Wendy Robertson, Gabrielle Schneider, Robin Shepard, \\ Laura Howe, Susan Silva and Colin Hall
}

AIDS Neurological Center and the Departments of Neurology, Microbiology and Immunology, Psychiatry, and Medicine, University of North Carolina at Chapel Hill, 751 Clinical Sciences, Chapel Hill, North Carolina, USA, 27599-7025

\begin{abstract}
Plasma viral burden has proven valuable in predicting the future course of systemic HIV related disease and the response to treatment. It is not known whether plasma or cerebrospinal fluid (CSF) viral burden can be used to predict onset of or response to treatment of nervous system disease. We propose a model of viral load mediated neurotoxicity underlying peripheral and central HIV associated neurological disease. The objective of this preliminary study was to assess the relationship of HIV associated neurological disease to quantitative viral load in plasma and CSF. 47 subjects $(\mathrm{HIV}-=10, \mathrm{HIV}+=37)$ participated in the study. Plasma and CSF samples were collected within a $3 \mathrm{~h}$ window. RT PCR (Roche Amplicor Monitor) was utilized to assess HIV-1 RNA viral load in both plasma and cell free (centrifuged) CSF. Subjects underwent concurrent comprehensive neurological and neuropsychological evaluations. In general, systemic viral load, as measured in plasma, was greater than that found in cell free CSF. Cell free CSF HIV RNA viral load was significantly correlated with neurological dysfunction, whereas plasma viral load was not. The sole subject with an elevated CSF viral load ( $>5$ Log 10), had HIV associated dementia (HAD) on clinical examination.
\end{abstract}

Keywords: viral load; HIV; dementia; HIV RNA PCR; CSF

\section{Introduction}

Central nervous system involvement is common in human immunodeficiency virus (HIV) infection (Robertson and Hall, 1992). Fifteen to $20 \%$ of AIDS patients will develop a progressive cognitive dysfunction known as HIV Associated Dementia (HAD; McArthur, 1992), and up to $80 \%$ will show pathological changes in the brain, including gliosis, neuronal loss and inflammation (Elder and Sever, 1988). The exact pathogenesis of these changes is not understood. There is no convincing evidence of neuronal infection by HIV, and there is considerable debate as to whether there is productive infection of astrocytes. An indirect mechanism has been postulated for neuronal cell death and HIV associated neurological disease. Possible etiological factors include viral products such as gp120, gene components such as tat, and products of immune activation such as quinolinic acid, cytokines and chemokines. Central to most of these hypotheses is the suggestion that the cerebrospinal fluid (CSF) and brain, which are immunologically protected and privileged compartments, may sequester HIV which could result in neurologic progression

Correspondence: KR Robertson

Received 1 July 1997; revised 7 October 1997; accepted 17 November 1997 independent of systemic viral burden, and which could potentially 'reseed' the systemic compartment.

In most instances, HAD occurs when the CD4+ count is below $0.200 \mathrm{~mm}^{3}$, but there are exceptions. Some patients have become demented while maintaining much higher CD4+ counts, while other patients maintain normal cognitive function despite having extremely low CD4+ counts for a protracted time. To design research studies and treatment strategies, it would be of great value to have a surrogate marker which effectively predicted the likelihood of symptomatic neurologic disease. The systemic plasma viral load has been shown to be significantly correlated with HIV disease progression (Mellors et al, 1996), and this raises the possibility that central nervous system (CNS) viral load may be of value in predicting CNS progression. Direct measurement of CNS viral load would require repeated brain biopsy, which is not clinically practical. However, it is possible that CSF viral burden may reflect CNS burden, or may independently correlate with progression of CNS disease.

Relatively little is known about the relationship of systemic plasma viral load to neurological disease, and even less is known about CSF viral 
load and the relationship to neurological and systemic disease. We have postulated that viral load mediates the neurotoxicity underlying HIV related neurological dysfunction (Robertson et al, 1997b). The objective of this preliminary study was to assess the relationship of HIV associated neurological disease to quantitative viral load in plasma and $\mathrm{CSF}$.

\section{Results}

Of the $37 \mathrm{HIV}+$ subjects, 36 plasma samples and 34 CSF samples were obtained. Viral load was below detectable limits in seven of the $36(19.4 \%)$ plasma samples, and 12 of the 34 (35.3\%) CSF samples. In general, systemic HIV RNA viral load as measured in plasma, was greater than that found in the CSF (Table 1, Figure 1). A significant relationship was found between plasma HIV RNA and CSF HIV RNA viral load $(r=0.42, P<0.05)$. Plasma HIV RNA was significantly related to systemic disease stage $(r=0.35, P<0.05)$ and CD4+ cell count $(r=-0.59$, $P<0.05$ ), but CSF HIV RNA was not. CSF HIV RNA was significantly correlated with CSF total nucleated cells $(r=0.46)$, monocytes $(r=0.43)$ and lymphocytes $(r=0.43)$. CSF HIV RNA was not significantly related to red blood cells, although only one CSF sample had greater than 100 (Mean=6, Median=0, range 0.192).

Three subjects had a CSF HIV RNA viral load greater than $3.69 \log 10$ (5000) copies/ml; two were classified with an ADC stage of 0.5 and one with ADC Stage 1. The sole subject who had frank dementia (ADC Stage 1) on clinical examination, had an elevated HIV RNA viral load of > 5.0 log 10 (100 000) copies/ml in the CSF, which was comparable to the plasma HIV RNA level. Six subjects who were classified as equivocal/minimal ADC stage (0.5) had CSF HIV RNA viral loads < $3.69 \log 10$ (5000) copies/ml.

Significant relationships were found with the quantitative neurological scoring procedure and CSF HIV RNA, but not with plasma HIV RNA (Table 2). Significant relationships were found between CSF HIV RNA and the Total Neurological score; and the domain scores of Frontal, Pyramidal, Extrapyramidal, Cerebellar, Spinal, and Autonomic. No significant relationships were found between CSF HIV RNA viral load and the domain scores of Cognitive, Cranial nerves, Sensory, and Peripheral. These relationships remained when systemic disease was accounted for by partialling out the variance associated with CD4+ cell counts. Analyses of variance found significant differences in HIV RNA viral load between subjects with ADC (equivalent $/ \mathrm{minimal} / \mathrm{mild}$ ) and those without any evidence of ADC (Figures 2 and 3). CSF HIV RNA was significantly increased in the ADC subjects

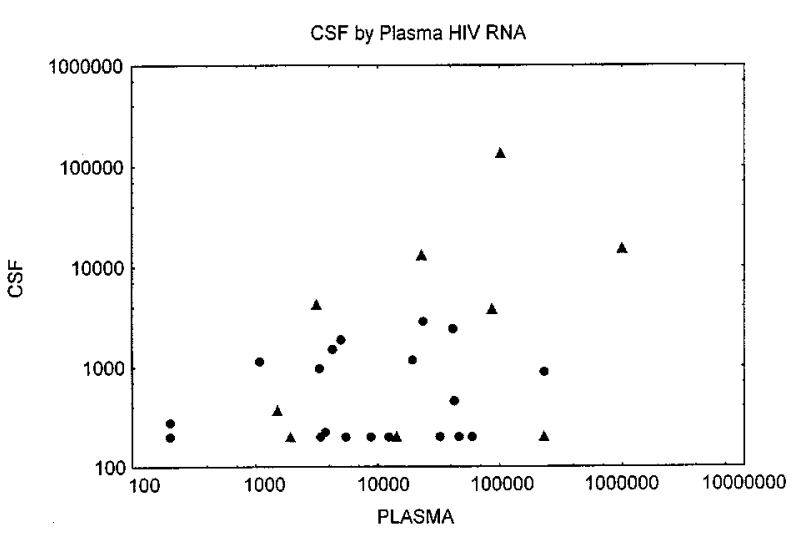

Figure 1 HIV RNA in paired plasma and CSF samples $(r=0.42$, $P<0.05)$. Note. Some observations overlap and are hidden. Circles denote normal subjects, triangles represent subjects with ADC (Stage 5 or 1 ).

Table 2 Correlations between quantitative neurological scores and plasma/CSF HIV RNA viral load.

\begin{tabular}{lcccc}
\hline & \multicolumn{2}{c}{ Plasma } & \multicolumn{2}{c}{ CSF } \\
& Correlation & $\mathrm{p}$ & Correlation & $\mathrm{p}$ \\
\hline Neuro Total & 0.06 & 0.71 & $\mathbf{0 . 3 8}$ & $\mathbf{0 . 0 3}$ \\
Cognitive & 0.03 & 0.84 & 0.21 & 0.25 \\
Frontal & 0.13 & 0.46 & $\mathbf{0 . 6 0}$ & $\mathbf{0 . 0 0 0 3}$ \\
Cranial nerves & 0.00 & 0.95 & -0.03 & 0.83 \\
Pyramidal & 0.20 & 0.26 & $\mathbf{0 . 4 7}$ & $\mathbf{0 . 0 0 6}$ \\
Extrapyramidal & 0.10 & 0.55 & $\mathbf{0 . 4 8}$ & $\mathbf{0 . 0 0 5}$ \\
Cerebellar & 0.15 & 0.40 & $\mathbf{0 . 4 3}$ & $\mathbf{0 . 0 1}$ \\
Spinal & 0.11 & 0.53 & $\mathbf{0 . 4 4}$ & $\mathbf{0 . 0 1}$ \\
Sensory & -0.00 & 0.98 & 0.09 & 0.60 \\
Peripheral & 0.14 & 0.43 & 0.17 & 0.34 \\
Autonomic & 0.07 & 0.66 & $\mathbf{0 . 6 9}$ & $\mathbf{0 . 0 0 0 1}$ \\
\hline
\end{tabular}

Table 1 Plasma and CSF HIV RNA viral load by systemic disease.

\begin{tabular}{|c|c|c|c|c|c|c|c|c|}
\hline & \multicolumn{2}{|c|}{ Total (33) } & \multicolumn{2}{|c|}{$A S X(9)$} & \multicolumn{2}{|c|}{$S X(5)$} & \multicolumn{2}{|c|}{ AIDS (19) } \\
\hline & $M$ & s.d. & $M$ & s.d. & $M$ & s.d. & $M$ & s.d. \\
\hline Age & 37.6 & 6.4 & 34.2 & 4.7 & 36.2 & 4.5 & 39.6 & 6.9 \\
\hline CD4+ & 266 & 237 & 541 & 179 & 399 & 50 & 93 & 99 \\
\hline Plasma HIV RNA & 3.89 & 1.01 & 3.59 & 1.23 & 3.35 & 0.83 & 4.16 & 0.89 \\
\hline CSF HIV RNA & 2.82 & 0.72 & 2.78 & 0.67 & 2.50 & 0.33 & 2.94 & 0.80 \\
\hline Neuro Total & 72.8 & 53.9 & 44.7 & 20.6 & 83.2 & 69.8 & 83.5 & 57.8 \\
\hline
\end{tabular}




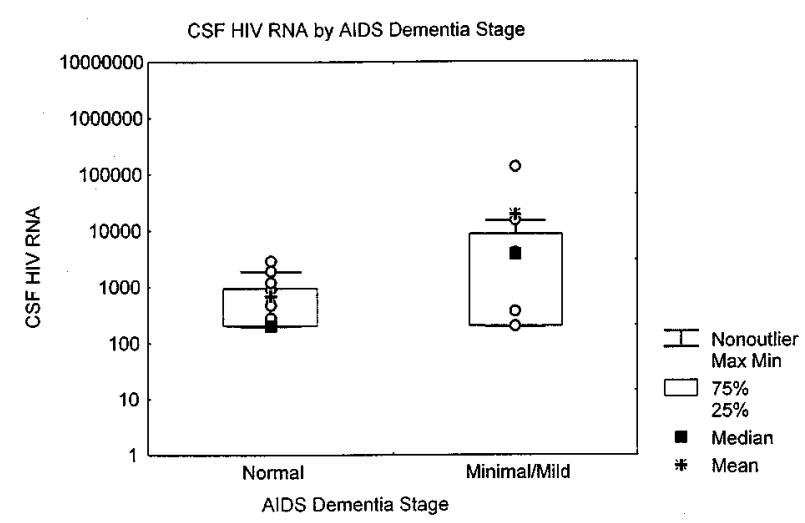

Figure 2 HIV RNA in the CSF by ADC stage. Significant increases in HIV RNA for subjects with ADC stage $>0 \quad(n=9)$ were found for CSF $(F=4.7, P<0.05)$. Note. Some observations overlap and are hidden.

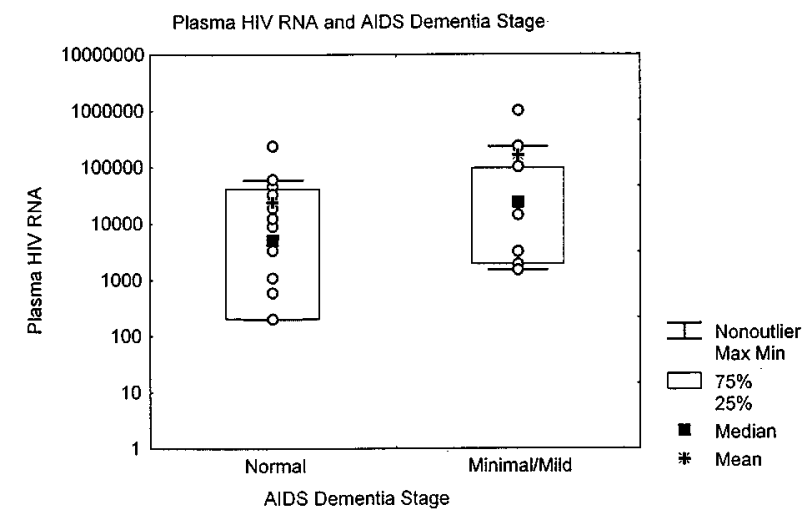

Figure 3 HIV RNA in the plasma by ADC stage. Significant increases in HIV RNA for subjects with ADC stage $>0 \quad(n=9)$ were found for plasma $(F=4.4, P<0.05)$. Note. Some observations overlap and are hidden.

(3.55, s.d.=1.03 log $10 \mathrm{copies} / \mathrm{ml}$ ) compared to those with normal ADC stage (2.63, s.d. $=0.43 \log 10$ copies/ml). Plasma HIV RNA was also significantly increased in the ADC group (4.42, s.d.=0.99 $\log 10$ copies/ml) relative to normal ADC stage (3.63, s.d. $=0.98 \log 10$ copies $/ \mathrm{ml}$ ). These differences remained significant when the subject with mild ADC was excluded. No significant differences in CSF red blood cells, total nucleated cells, lymphocytes or monocytes were found between these groups.

\section{Discussion}

HIV RNA viral load in the CSF was found to be related to the severity of neurological dysfunction in the present study. As HIV RNA in the CSF increased, neurological dysfunction, as measured by the quantitative scoring procedure, increased. In addition, significant CSF HIV RNA increases were found in subjects with ADC (Stage 0.5 equivocal/ minimal or Stage 1 mild) compared to those with no evidence of ADC (Stage 0). Of clinical interest, the only subject with frank dementia (ADC Stage 1) had the highest CSF viral load (>5.0 log 10). This subject progressed rapidly, and expired within 3 months of evaluation.

A relationship was found between plasma HIV RNA viral load and that in the centrifuged CSF. Although studies assessing viral load in uncentrifuged CSF have found a significant relationship with plasma viral load (McArthur et al, 1997; Ellis et al, 1997), a study which assessed HIV RNA viral load in centrifuged CSF compared to plasma found no correlation (Brew et al., 1997).

This study provides preliminary support for viral load mediated neurotoxicity as an underlying factor in the neurological dysfunction seen with HIV. We believe that cumulative CNS/CSF viral load over the course of the disease may correlate with the degree of CNS dysfunction, overwhelming host defenses (e.g. the blood brain barrier), plasticity and cognitive reserves by endstage. We have previously reported a preliminary study showing a relationship between increased plasma viral load and severity of neurologic disease (Robertson et al, 1997b). Clinical observations also provide circumstantial support for such a relationship. At the time of initial infection, when there is a known high viral peak, acute neurological disease can occur (Carne et al, 1985; Varma et al, 1989; Cooper et al, 1985). During the asymptomatic stages, lower levels of virus in plasma or CSF are generally found (Izopet et al, 1996; Garcia et al, 1997; Conrad et al, 1995; Schmid et al, 1994), but virus remains active in the lymphatic tissues (Pantaleo et al, 1993; Embretson et al, 1993). There is continued dispute as to whether there is any progressive neurologic decline during the asymptomatic phase (Sidtis and Price, 1990; Atkinson and Grant, 1994). The level of viral load associated neurotoxicity is lower and intermittent, resulting in little or subclinical neurological symptoms. There is general agreement that progressive neurological disease is a common feature of late SX stages and AIDS. In late symptomatic stages, it again becomes relatively easy to detect virus in both plasma and CSF (Coombs et al, 1989; Hollander and Levy, 1987).

CSF viral load cannot be presumed to be equivalent to brain viral load. However, repeated brain biopsy is not clinically feasible and it is clearly important to establish whether CSF can be used as a surrogate marker. If so, then observation of changes in CSF viral load may have a vital role in the prediction and prognosis of CNS dysfunction and in the choice of antiretroviral treatment regimens. Our own and other groups are engaged in studies addressing this important clinical question 
(Robertson et al, 1997b; Brew et al, 1997; Johnson et al, 1996; McArthur et al, 1997; Ellis et al, 1997).

\section{Materials and methods}

\section{Subjects}

Forty seven subjects voluntarily participating in an AIDS Neurological Center study of gender differences in HIV viral load and neurological disease progression were included in this report. Thirty seven HIV seropositive subjects $(22 \%$ were females and $54 \%$ were ethnic minority) and 10 were HIV seronegative female controls $(20 \%$ were ethnic minority). The female controls had a mean age of 41.9 years (s.d.=5.89) and 14.3 (s.d.=2.26) years of education. The HIV+ subjects had a mean age of 38.3 (s.d.=6.53) years and 12.9 (s.d.=2.10) years of education. The controls had a mean absolute CD4 cell count of $0.993 \mathrm{~mm}^{3}$ (s.d.=0.199) and the HIV seropositives had a mean of $0.259 \mathrm{~mm}^{3}$ (s.d.=0.227). Of the HIV seropositive subjects, 11 were asymptomatic (ASX, CDC stages A1,2), 4 were symptomatic (SX, B1,2) and 22 had AIDS (A3, B3, C1-3). Thirty three of the HIV+ subjects were on antiretroviral therapy, 19 were on combination therapy and four had no current treatment.

\section{Instruments}

Quantitative HIV-1 RNA viral load was measured by the Roche Amplicor Monitor RT-PCR kit. The AIDS Clinical Trials Group (ACTG) Full neurological evaluation was utilized (Price and Sidtis, 1990). This contains a global assessment of HAD, termed AIDS Dementia Complex (ADC) Stage, varying from equivocal (0.5) to severe (3.0) dementia. In addition, a quantitative scoring procedure for the neurological evaluation was implemented, increasing the sensitivity of the instrument and providing domains of functioning (Robertson et al, 1997a). This procedure provides a weighted scoring approach to the items of the neurological exam, and yields an

\section{References}

Atkinson JH, Grant I (1994). The natural history of neuropsychiatric disorders in HIV-1 Infection. Psych Clin N Amer 17: 17-33.

Benjamini Y, Hochberg Y (1995). Controlling the false discovery rate: A practical and powerful approach to multiple testing. Journal of the Royal Statistical Society, B, 57(1): 289-300.

Boom R, Sol C, Salimans M, Jansen C, WertheimvanDillen P, van der Noorda J (1992). A method for HIV-1 RNA isolation. J Clin Microbiol, 28: 495-503.

Brew B, Pemberton L, Cunningham P, Law MG (1997). Levels of human immunodeficiency virus type 1 RNA in cerebrospinal fluid correlate with AIDS dementia stage. J of Infectious Disease, 175(4): 963-966. overall Neurological Total score as well as scores for the domains of Cognitive, Frontal, Pyramidal, Extrapyramidal, Cranial Nerves, Cerebellar, Spinal, Autonomic, Sensory, and Peripheral.

\section{Procedure}

Specimens for viral load and immune functioning were drawn within $8 \mathrm{~h}$ of the neurological evaluation. Blood and CSF samples were drawn within $3 \mathrm{~h}$ of each other. Prior to analyses, xanthochromic CSF samples were excluded and CSF samples were centrifuged to remove cells. Samples which contained inhibitors of the Roche RT - PCR assay, were rerun following isolation of the HIV RNA using the silica bead extraction procedure (Boom et al, 1992; Dyer et al, 1996). Levels below detection were assigned values of 200. Neurological evaluations were completed prior to, and therefore, blind to the viral load results. To control for error associated with multiple statistical comparisons, the False Discovery Rate (FDR) procedure was used to adjust significance levels where multiple correlations were computed (Benjamini and Hochberg, 1995; Williams et al, 1994). The FDR is a sequential step up procedure utilized to adjust alpha for excessive power and reduce Type I errors when performing multiple comparisons.

\section{Acknowledgements}

This work was supported by grants from the National Institute of Neurological Diseases and Stroke (P01-NS26680, R01-NS34234), National Institutes of Allergy and Infectious Diseases (AI25868) and the National Center for Research Resources (GCRC, RR00046). Portions of this work were presented at the 4th Conference on Retroviruses and Opportunistic Infections, Washington, DC, January, 1997.

Carne CA, Elkington S, Preston F, Tedder RS, Sutherland S, Daly H, Craske J (1985). Acute encephalopathy coincident with seroconversion for anti-HTLV-III. Lancet, 2: 1206-1208.

Conrad AJ, Schmid P, Syndulko K, Singer EJ, Nagra RM, Tourtellotte W (1995). Quantifying HIV-1 RNA using the polymerase chain reaction on cerebrospinal fluid and serum of seropositive individuals with and without neurologic abnormalities. J AIDS and Human Retrovirology, 10: 425-435.

Coombs RW, Collier AC, Allain JP, Nikora B, Leuther M, Gjerset G, Corey L (1989). Plasma viremia in human immunodeficiency virus infection. $N$ Eng J Med, 321: $1626-1631$ 
Cooper DA, MacLean P, Finlayson R, Michelmore H, Gold J, Donovan B, Barnes T, Brooke P, Perry R (1985). Acute AIDS retrovirus infection: definition of a clinical illness with seroconversion. Lancet, 1: $537-$ 540.

Dyer JR, Gilliam BL, Eron JJ, Grosso L, Cohen MS, Fiscus SA (1996). Quantitation of human immunodeficiency virus type 1 RNA in cell-free seminal plasma: Comparison of NASBA with Amplicor reverse transcription-PCR amplification and correlation with quantitative culture. J Virological Methods, 60: 161170.

Elder GA, Sever JL (1988). AIDS and Neurological Disorders: An Overview. Ann of Neurology, 23: S4S6.

Ellis RJ, Hsia K, Spector S, Nelson J, Heaton R, Wallace M, Abramson I, Atkinson H, Grant I, McCuthan A, HIV Neurobehavioural Research Center Group (1997). Cerebrospinal fluid HIV-1 RNA levels are elevated in neurocognitively impaired individuals with AIDS. Ann Neurol, 42: 679-688.

Embretson J, Zupancic M, Ribas J, Burke A, Racz P, Tenner-Racz K, Haase A (1993). Massive covert infection of helper $\mathrm{T}$ lymphocytes and macrophages by HIV during the incubation period of AIDS. Nature, 362: $359-362$.

Garcia F, Vidal C, Gatell J, Miro J, Soriano A, Pumarola $\mathrm{T}$ (1997). Viral load in asymptomatic patients with CD4+ lymphocyte counts above 500. J AIDS, 11: 5357.

Hollander H, Levy JA (1987). Neurologic abnormalities and recovery of human immunodeficiency virus from cerebrospinal fluid. Ann Intern Med, 106: 692-695.

Izopet J, Poggi C, Dussaix E, Mansuy JM, Cubaynes L, Profizi N, Lafeuillade A, Marchou B, Massip P, Sayada C, Puel J (1996). Assessment of a standardized reverse-transcriptase PCR assay for quantifying HIV-1 RNA in plasma and serum. Journal of Virological Methods, 60(2): 112-129.

Johnson RT, Glass JD, McArthur JC, Chesebro BW (1996). Quantitation of HIV in brains of demented and nondemented patients with AIDS. Ann Neurology, 39: $392-395$.

McArthur JC (1992). HIV dementia: incidence and risk factors. J Neurol Sciences, 113: 131.

McArthur JC, McClernon D, Cronin M, Nance-Sproson T, Saah A, St Clair M, Lanier R (1997). Relationship between HIV-Associated Dementia and viral load in cerebrospinal fluid and brain, Ann Neurol, 42: $689-$ 698.
Mellors J, Rinaldo C, Gupta P, White R, Todd J, Kingsley $\mathrm{L}$ (1996). Prognosis in HIV-1 infection predicted by the quantity of virus in plasma. Science, 271: 11671170.

Pantaleo G, Grazos C, Demarest J, Butini L, Motroni M, Fox C, Orenstein J, Kotler D, Fauci A N(1993). HIV infection is active and progressive in lymphoid tissue during the clinically latent stage of disease. Nature, 362: $355-358$.

Price RW, Sidtis JJ (1990). Evaluation of the AIDS dementia complex in clinical trials. J AIDS, 3 (Supp (2)): S51-S60.

Robertson K, Kapoor C, Price R, Sidtis J, Robertson W, van der Horst C, Hall C N (1997a). The Neurological Examination in AIDS: Functional Domains and Quantitative Scoring. American Academy of Neurology Meeting, Boston, MA, April, 1997.

Robertson K, Fiscus S, Wilkins J, van der Horst C, Hall C (1997b). Viral load and neuropsychological functioning in HIV seropositive individuals: a preliminary descriptive study. J of NeuroAIDS, 1(4): 7-15.

Robertson KR, Hall CD (1992). HIV related mild cognitive impairment and AIDS dementia complex. Seminars in Neurology, 12(1): 18-27.

Schmid P, Conrad AJ, Syndulko K, Singer EJ, Handley D, Li X, Tao G, Fahy-Chandon B, Tourtellotte W (1994). Quantifying HIV-1 proviral DNA using the polymerase chain reaction on cerebrospinal fluid and blood of seropositive individuals with and without neurologic abnormalities. J AIDS, 7: 777-788.

Sidtis JJ, Price RW (1990). Early HIV-1 infection and the AIDS dementia complex. Neurology, 40: 323-326.

Varma VA, Hunter S, Tickman R, Srinivasan A, Swan D (1989). Acute fatal HIV encephalitis with negative serologic assays for antibody and antigen: diagnosis by polymerase chain reaction. $N$ Engl J Med, 320: 1494-1495.

Williams V, Jones L, Tukey J (1994). Controlling error in multiple comparisons, with special attention to the National Assessment of Educational Progress. $\mathrm{Na}$ tional Institute of Statistical Sciences, Technical report 33. 